\title{
Molecular aspects of monoamine oxidase B
}

\author{
Rona R. Ramsay
}

Biomedical Sciences Research Complex, University of St Andrews, North Haugh, St Andrews, KY16 9ST, United Kingdom

\section{Corresponding author:}

Rona R. Ramsay, School of Biology, BMS Building, University of St Andrews, North Haugh, St Andrews, KY16 9ST, United Kingdom

Email: rrr@st-andrews.ac.uk

Tel: +441334463411

\section{Graphical abstract}

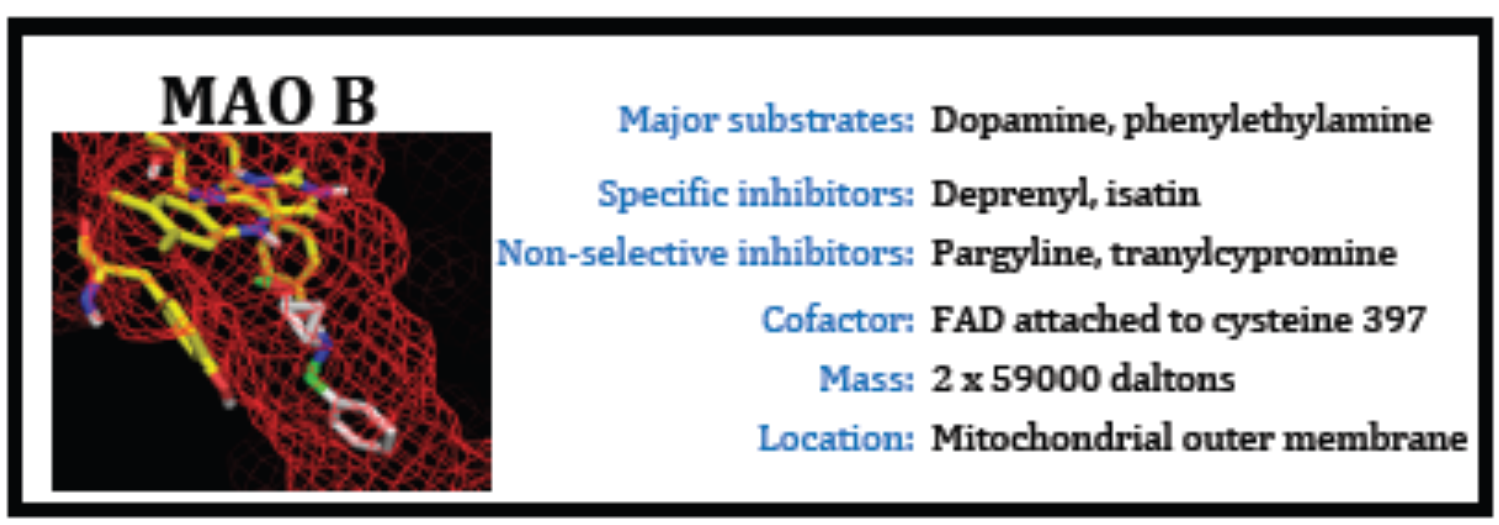

\section{Highlights}

-MAO B activity depends on both amine and oxygen concentrations

-Expression, activity, and regulation of MAO $B$ is discussed

-MAO B is elevated in Alzheimer's and Parkinson's Diseases

- Irreversible modification of MAO B by drugs against neurodegeneration

-Structure-based multi-target drug design and computational approaches 


\section{Abstract}

Monoamine oxidases (MAO) influence the monoamine levels in brain by virtue of their role in neurotransmitter breakdown. MAO B is the predominant form in glial cells and in platelets. MAO B structure, function and kinetics are described as a background for the effect of alterations in its activity on behavior. The need to inhibit MAO B to combat decreased brain amines continues to drive the search for new drugs. Reversible and irreversible inhibitors are now designed using data-mining, computational screening, docking and molecular dynamics. Multi-target ligands designed to combat the elevated activity of MAO B in Alzheimer's and Parkinson's Diseases incorporate MAO inhibition (usually irreversible) as well as iron chelation, antioxidant or neuroprotective properties. The main focus of drug design is the catalytic activity of MAO, but the imidazoline $\mathrm{I}_{2}$ site in the entrance cavity of MAO B is also a pharmacological target. Endogenous regulation of MAO B expression is discussed briefly in light of new studies measuring mRNA, protein, or activity in healthy and degenerative samples, including the effect of DNA methylation on the expression. Overall, this review focuses on examples of recent research on the molecular aspects of the expression, activity, and inhibition of MAO B.

\section{Keywords}

Monoamine oxidase B; kinetics; drug design; neurotransmitter levels; platelet

\section{Abbreviations}

Alzheimer's Disease, AD; Parkinson's Disease, PD; dopamine transporter, DAT; serotonin transporter, SERT; noradrenaline transporter, NET; the vesicular transporter, VMAT; Gprotein coupled receptor, GPCR; induced pluripotent stem cells, iPSC; serotonin reuptake inhibitor, SSRI; brain-derived neurotrophic factor, BDNF; multi-target designed ligands, MTDL; $I_{50}$, the concentration of compound required to inhibit a specified assay by $50 \%$; $\mathrm{K}_{\mathrm{i}}$, a kinetically measured inhibitor dissociation constant.

Word count - approx 5490 (excluding references). Abstract 196 words. 


\section{Introduction}

The monoamine neurotransmitters dopamine, serotonin, and noradrenaline influence neuronal signaling in the brain. Changes in the monoamine system are associated with depression, addiction, aggression, and amine levels decrease in neurodegenerative diseases.

The balance between the synthetic enzymes and the breakdown enzymes sets the overall level of amines in the brain. The amount of the neurotransmitter amines available for signaling is strongly dependent upon the reuptake carriers (DAT, SERT, NET) and on the vesicular transporter (VMAT) driven by the proton gradient generated by the vesicular ATPase. Neurotransmitter release is controlled by signaling pathways and modulated by pre-synaptic auto-receptors. The post-synaptic effect of the neurotransmitters depends on specific families of receptors $\left(\mathrm{D}_{1-5} 5-\mathrm{HT}_{1-7}\right.$ and adrenergic receptors, and the related TAAR1 for trace amines), most of which are G-protein coupled receptors (GPCRs) - see (Beaulieu et al., 2015, McCorvy and Roth, 2015), and the IUPHAR database of the genetic and functional properties of receptors (http://www.guidetopharmacology.org/) (Sharman et al., 2011).

$\mathrm{MAO}$, as the major metabolic enzyme for the deactivation of the monoamine neurotransmitters, is a key target in neuro-psychopharmacology. Its inhibitors, used as antidepressant drugs for over 50 years, have been shown to raise brain amine levels. The observation that inhibition of MAO increases monoaminergic function has supported a long-running drug discovery effort to find novel drugs that inhibit MAO to treat mood and degenerative disorders, including depression, aggression, schizophrenia, hyperactivity, Parkinson's Disease (PD), and Alzheimer's Disease (AD) (Oreland, 2004, Murphy et al., 2006, Oreland et al., 2007, Fisar et al., 2010, Bortolato and Shih, 2011, Song et al., 2013). In current efforts to discover compounds to combat neurodegeneration in PD and $A D$, MAO inhibition is a key feature in multi-target designed ligands (MTDL) that are intended to help spare the decreasing levels of neurotransmitters (Ramsay, 2012, Zheng et al., 2012, Bautista-Aguilera et al., 2014). A further benefit of inhibiting MAO is the decreased production of ammonia and hydrogen peroxide that accompany amine oxidation, thus reducing oxidative stress (Kaludercic et al., 2014, Ooi et al., 2015). 
MAO iso-enzymes are important because their activity sets the monoaminergic tone of the brain. The interest in drug design to increase monoamine levels is reflected in a constant stream of reviews. Several reviews in the last 5 years provide the wider background to MAO (Bortolato and Shih, 2011, Youdim and Reiderer, 2011, Ramsay, 2012, Song et al., 2013, Fowler et al., 2015) This review will include key references for the established facts but focus on examples of recent research on the expression, activity and inhibition of MAO B.

\section{MAO influences the monoamine levels in brain}

\subsection{Lower MAO activity means higher amine levels and vice versa}

That low MAO activity is associated with higher amines has been demonstrated in knockout mice (or MAO-deficient humans) and in both animals and humans after inhibitor treatment. MAOA/B knockout mice displaying anxiety-like symptoms have greatly elevated monoamine levels (Chen et al., 2004). Humans lacking MAO B have greatly elevated levels of phenylethylamine (Murphy et al., 1990). In rats, numerous microdialysis experiments have been conducted to measure amine changes in different disease models (including addiction) or to assess the effects of MAO inhibitors (for example, (Butcher et al., 1990, Lamensdorf et al., 1996, Gal et al., 2005, Bazzu et al., 2013, Sader-Mazbar et al., 2013, Bolea et al., 2014)). After treatment with MAO inhibitor, mice showed significantly higher noradrenaline and serotonin levels and significantly lower metabolites (including DOPAC from dopamine) (Lum and Stahl, 2012).

In human brain, MAO A levels measured by $\left[\mathrm{C}^{11}\right]$-clorgyline binding in PET scans showed a clear elevation of activity associated with depression (Meyer et al., 2006). Other studies have examined the changes in metabolites associated with polymorphisms confirming that higher activity alleles show more metabolism of dopamine, noradrenaline and serotonin (Aklillu et al., 2009, Andreou et al., 2014). Elevated MAO activity had already been observed in AD-type dementia in 1980 (Adolfsson et al., 1980). Later work has established that it is MAO B activity that increases with age in human brain (associated with gliosis) and is elevated in several degenerative diseases. Recently, a range of experimental techniques have been used to demonstrate increased MAO B activity in Huntington's, Alzheimer's and Parkinson's diseases (Kennedy et al., 2003, Zellner et al., 2012, Woodard et al., 2014, Ooi et al., 2015). For example, in a new 
approach, genes related to the dopaminergic system were studied in iPSC neurons from twins without and with PD. Genes for the dopamine receptors and for dopamine synthesis, uptake, release, and metabolism were found to be differentially expressed in PD neurons compared to those from the identical twin (Woodard et al., 2014). MAO B was higher by almost 1.5-fold in both of the PD-affected persons compared to their unaffected twin.

\subsection{MAO inhibition raises brain amine levels}

2.2.1 Animal - microdialysis. As noted above, microdialysis has been used to demonstrate changes in amine levels in the brain. Improved methods enable more sophisticated experimental design and analysis. The improvement in the separation and quantification of the monoamines and their metabolites (De Benedetto et al., 2014), with excellent temporal resolution (1min (Gu et al., 2015)), and combination with electrophysiology (Flik et al., 2015) has brought direct measurements of brain amines in disease models or in response to drugs into standard practice. In combination with behavioural studies, microdialysis is a very useful experimental tool for the characterization of new models, such as birds (Ihle et al., 2015), that will lead to better understanding of the influences of monoamines on behavior. In another example, MAO B inhibition has long been used as an adjunct to DOPA therapy for PD to spare dopamine by decreasing its metabolism. Microdialysis in rats has confirmed that deprenyl treatment results in higher dopamine levels for longer (Malmlof et al., 2015).

2.2.2 Human studies. In order to see elevation of brain amines in humans, more than $90 \%$ inhibition of MAO is required (Fowler et al., 2015). The altered amine balance as a result of MAO inhibition then initiates a process of change in the CNS, with a lag of around three weeks before effects on mood are detected. Conversely, most of the MAO inhibitors in common use are irreversible inhibitors so recovery from inhibition is slow (Fowler et al., 1996, Zajecka and Zajecka, 2014). It should be noted that, although PET scans are the method of choice for measuring the levels of active MAO in the brain, the method does not measure changes in the brain amines (Fowler et al., 2015).

Human urinary metabolites have given insight into amine metabolism in humans since the 1970s. Analysis of urine samples was used to identify perturbed amine metabolism in males with abnormal behavior due to a terminating point mutation in the MAO A gene (Brunner et al., 1993). Interestingly, the urinary metabolites for MAO A and MAO B 
deficiencies gave distinctly different patterns. In humans lacking MAO A, deaminated catecholamines decreased and O-methylated metabolites increased. In contrast, men with the MAO B gene deletion excrete phenylethylamine, a trace amine normally metabolised by MAO B (Lenders et al., 1996).

Human plasma levels of metabolites are higher than those in urine but follow similar trends (see for example (Hyland, 2008, Mercimek-Mahmutoglu et al., 2014).

Pharmacokinetic assessment of MAO B inhibitors routinely measured metabolites in plasma and MAO B inhibition in platelets (Dingemanse et al., 1996).

Although use of human cerebrospinal fluid (CSF) is more invasive for the patient, measurement of neurotransmitters and their metabolites in CSF is considered to give the most direct insight into the brain levels (Hyland, 2008). However, large inter-individual variations (Dhondt and Forzy, 2003) mean that comparative measurements during treatment are more useful than single values. One example, a study on the effects of the irreversible MAO inhibitor called F70, demonstrated that dopamine and serotonin were raised as a consequence of the treatment, and the metabolites were significantly lower (Moron et al., 2000).

Serotonin toxicity events provide strong evidence for raised amine levels in humans. The clinical symptoms of serotonin toxicity arise when MAO inhibitors (especially nonselective or MAO A inhibitors) are administered in patients already taking serotonin reuptake inhibitors (SSRIs) (Gillman, 2011).

\subsection{MAO inhibition decreases the toxic by-products of MAO activity}

MAO activity generates $\mathrm{H}_{2} \mathrm{O}_{2}$ that can damage molecules in nearby parts of the cell. Tyramine added to isolated mitochondria increased the production of $\mathrm{H}_{2} \mathrm{O}_{2}$ by 1.6 $\mathrm{nmol} / \mathrm{min} / \mathrm{mg}$ protein, and more than doubled the single-strand breaks in mitochondrial DNA (Hauptmann et al., 1996). Inhibition of MAO in rat brain by rasagiline (MAO B specific) or clorgyline (MAO A specific) decreased lipid peroxidation by half (Aluf et al., 2013). Chronic rasagiline treatment also increased defenses against oxidative stress as a consequence of the up-regulated expression of BDNF, Bcl-2 and catalase in the brains of aged mice (Weinreb et al., 2015). 
The oxidative stress arising from $\mathrm{H}_{2} \mathrm{O}_{2}$ generated by MAO activity is likely to be higher in glial cells than in neurons. In neurons, the vesicular reuptake competes for amine molecules with MAO A (or MAO B in serotonergic neurons). Although amine penetration into glial cells is less, all amine molecules are available for oxidation by MAO. It can be speculated that in the presence of SSRIs, oxidative stress would increase due to increased diffusion of amines from the synaptic cleft. In the periphery, platelet MAO B oxidises the serotonin very slowly, but any other amines penetrating the platelet will contribute to $\mathrm{H}_{2} \mathrm{O}_{2}$ generation. The contribution of amines to oxidative stress significant to physiology has been studied in heart and attributed to MAO A in the cardiomyocytes. Activated platelets release serotonin during cardiac ischemia, some of which is taken up by amine transporters into the cardiomyocytes. After reperfusion, serotonin is metabolised by MAO A generating $\mathrm{H}_{2} \mathrm{O}_{2}$. Damage and cardiomyocyte apoptosis can be prevented by inhibition of the amine transporter or MAO, or by antioxidants (Bianchi et al., 2005). Studies in this area since 2002 when the importance of amine plus MAO-generated oxidative stress became apparent, and some insights into the mechanisms involved are reviewed in (Kaludercic et al., 2014). More recently, MAO has been noted as a source of oxidative stress in diabetes (Sturza et al., 2015). These associations expand the application of MAOI to heart disease and vascular damage as reviewed in (Deftereos et al., 2012).

\section{Monoamine Oxidase B expression}

\subsection{Regulation of MAO B expression}

MAO $A$ and $B$ genes have identical exon-intron organization but are regulated differently (reviewed in (Shih and Chen, 2004)). Both promoters are GC-rich and regulated by transcription factor $\mathrm{Sp} 1$, but the Sp1 sites are organized differently. The promoter organization and transcriptional regulation for MAO B are summarized in Fig. 1. MAO B expression is up-regulated by decreased methylation, as observed in smokers (Launay et al., 2009). This was tested and confirmed in HeLa cells incubated with a DNA methyltransferase inhibitor resulting in decreased methylation of the MAO B promoter and increased MAO B expression (Wong et al., 2003). MAO B expression is also modulated by retinoic acid, by glucocorticoids and by the sex steroids (reviewed in (Shih et al., 2011). 


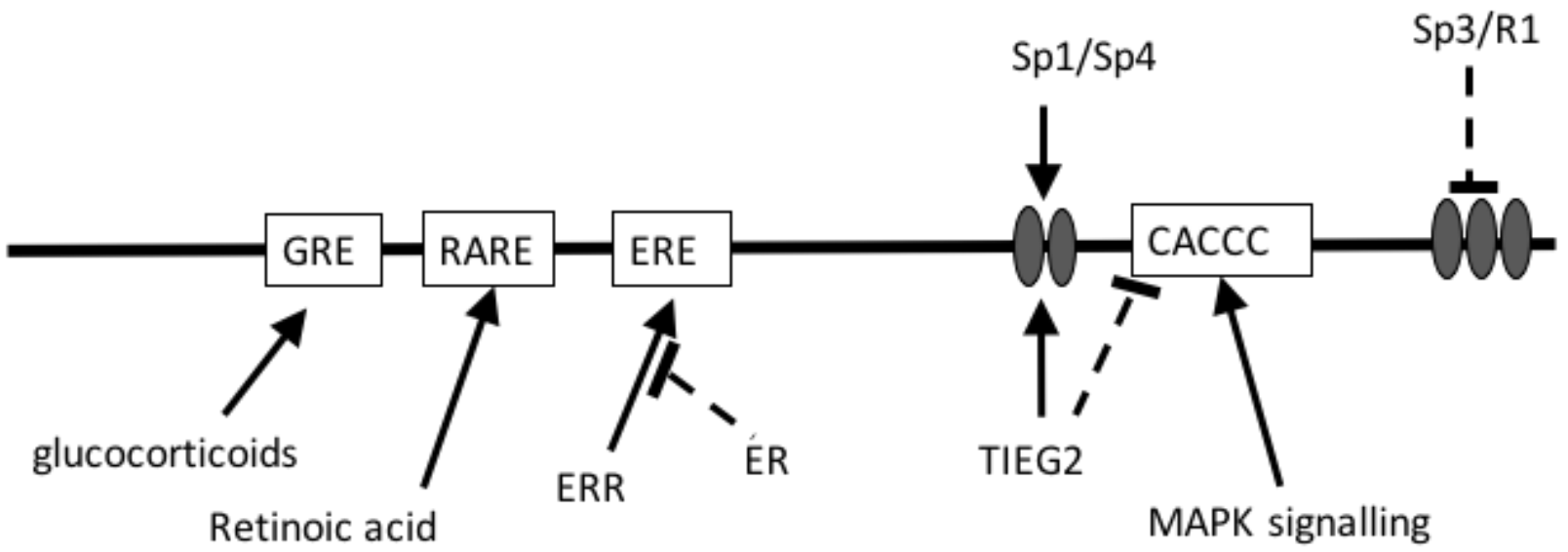

Fig. 1. Promotor and transcriptional regulation of MAO B (adapted from (Shih et al., 2011).

\subsection{Human genetic and epigenetic variations}

Complete lack of MAO A and MAO B was discovered in Norrie's disease where part of the $\mathrm{X}$ chromosome is deleted. The affected males have no MAO B activity in platelets and marked changes in the amine metabolites (Murphy et al., 1990). Subsequently, males with micro-deletions were identified, revealing that MAO A deletion has a strong influence on both amine metabolism and behavior, whereas those with the MAO B micro-deletion showed neither mental retardation nor abnormal behavior. The biggest change in the absence of MAO B is the excretion of large quantities of PEA (Lenders et al., 1996, Shih et al., 1999).

Genetic studies have identified polymorphisms that affect expression levels of MAO, the main reason for higher or lower MAO activity in individuals (Manuck et al., 2000, Balciuniene et al., 2002) leading to many clinical studies relating behavior to MAO status. Large numbers of genetic studies have looked for polymorphisms in MAO B that are different in control and experimental groups with altered behavior. Only one polymorphism in MAO B affects activity: a single nucleotide alteration (A644G in intron 13 of the MAO B gene) results in lower enzyme activity and increased levels of synaptic monoamine concentrations. Whether using genetics or platelet activity measurements, low MAO B activity results in behavioral disinhibition, risky behaviour, and poor impulse control (for reviews see (Oreland and Hallman, 1995, Bortolato et al., 2009). Studies looking for association of the $\mathrm{A} 644 \mathrm{G}$ polymorphism with depression, schizophrenia, autism, or 
addictions have produced mixed results. A recent meta-analysis of twenty studies with 2846 patients and 3508 controls provides evidence for a slightly increased risk of PD with the $\mathrm{G}$ allele (Liu et al., 2014). The A allele is associated with slightly lower platelet MAO B activity (Garpenstrand et al., 2000), so the meta-analysis is consistent with the observation of the lower incidence of PD in smokers where MAO B is inhibited.

Epigenetics can play a role in determining the level of MAO activity expressed, as indicated by a study comparing the methylation state of the MAO A gene with the brain MAO A activity in men (Shumay et al., 2012). Increase methylation on MAO A, MAO B and COMT genes was found in borderline personality disorder but activity was not measured (Dammann et al., 2011).

\subsection{Expressed protein levels}

MAO B is highly expressed in liver and is the predominant form of MAO in platelets, glial cells and serotonergic neurons. Note that rats, mice and humans have slightly different distribution of the MAO isoenzymes (Youdim and Finberg, 1983). MAO B is low in the neonate both in mice and humans, but increases rapidly after birth (Holschneider et al., 2001, Nicotra et al., 2004).

Many studies have used platelets to establish associations between MAO B and neuropathologies or behavioural aberations, measuring mRNA, protein or activity. (Note that these measurements may or may not correlate with each other, so cannot be used interchangeably.) Levels of MAO B in platelets at least indicate the genetically determined expression levels in brain. The premise is sufficiently established to allow a platelet protein biochip, developed for detection of an Alzheimer's disease-specific phenotype, to include MAO B (Veitinger et al., 2014a, Veitinger et al., 2014b). This technical advance in diagnosis could be expanded for other neuropathologies or behavior with known associations to MAO B, for example, alcoholism (Coccini et al., 2002).

Although platelets are a convenient source for measurement of MAO B as a biomarker, the best method to examine the levels of MAO A and MAO B in the brain is by Positron Emission Tomography (PET). Multiple ligands for MAO A or for MAO B are now available and the pharmacokinetics are well understood, as reviewed in (Fowler et al., 2015) . An irreversible ligand such as deprenyl requires active MAO B to form the adduct, so serves 
as an in vivo measurement of both protein and activity; reversible ligands measure only protein levels.

A.

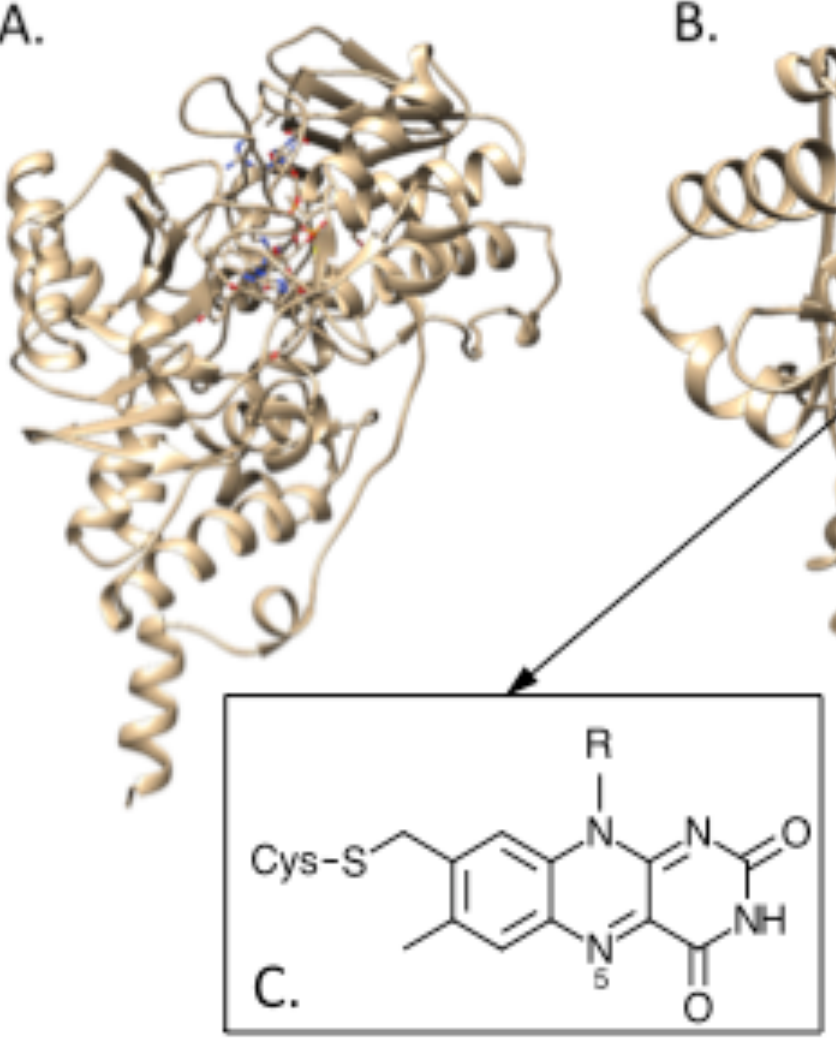

B.

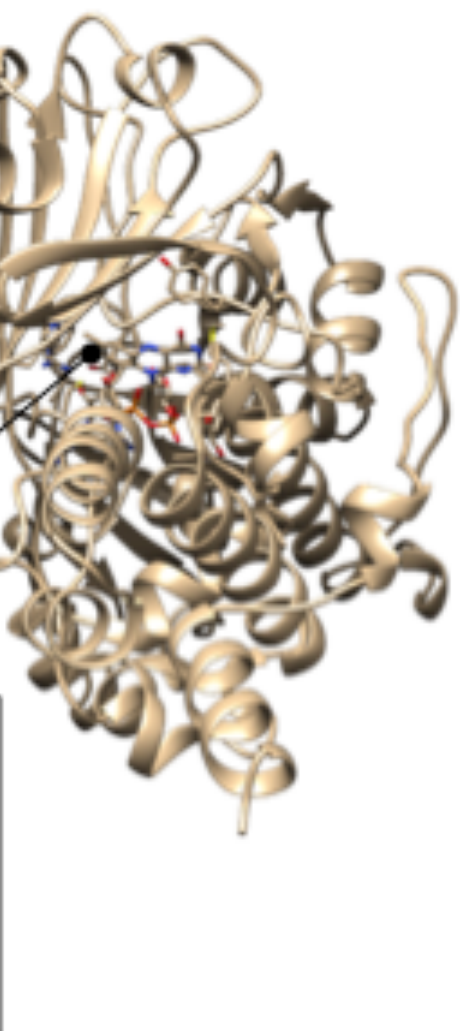

Fig. 2. MAO B monomer structure. The two views of $M A O B$ were prepared from pdb file 1oja using AutoDock. The bound isatin was removed, the covalent bond between the FAD and Cys 198 inserted, and hydrogen atoms added. The FAD and the tyrosines that form the aromatic cage around the active site are shown as sticks; the general structure is shown in ribbon form. A. Side view showing the helix that is buried in the membrane; the active site cavity bounded by FAD and three tyrosines is seen in the middle. B. View looking up from the membrane through the entrance cavity to the active site.

\section{Molecular properties of MAO B}

\subsection{MAO B protein: structure, active site and $I_{2}$ site}

MAO B forms a homo-dimer in which each subunit (59000 daltons) contains one covalently-bound FAD linked to cysteine 397 (Edmondson et al., 2009). Each monomer (Fig. 2) has one helix buried in the mitochondrial outer membrane and further surface area thought to associate with the membrane. In the membrane-bound dimer, the distance 
between the N5 atoms of the two FAD molecules, measured by pulsed dipolar ESR spectroscopy after irreversible modification of the FAD with a nitroxide spin-labeled irreversible inhibitor, was $4.4 \mathrm{~nm}$ (Upadhyay et al., 2008, Edmondson et al., 2009).

In general terms, MAO B has a larger but more restricted binding cavity than does MAO $A$, as described in detail in a comparative review of the structures of the two enzymes (Edmondson et al., 2007). In MAO B, two amino acid side chains (lle199 and Tyr326) form a "gate" between the entrance cavity and the catalytic site. The gate is easily opened by movement of these side chains, to accommodate large ligands, as seen in the crystal structures for MAO B with, for example, deprenyl (2BYB (Binda et al., 2005a)) or ASS234 (4CRT (Esteban et al., 2014)). It can also be stabilized in the closed position after inactivation with tranylcypromine (TCP) (Bonivento et al., 2010, McDonald et al., 2010). The closed conformation organizes the entrance cavity of MAO B into a binding site for imidazoline ligands of the $\mathrm{I}_{2}$ type. In the crystal structure of TCP-inactivated MAO B, the $\mathrm{I}_{2}$ ligand (2-BFI) is held in place by the closed gate residues, lle199 and Tyr326, and by Pro102 and Phe99. High affinity (nM) binding to MAO B was first demonstrated using various $I_{2}$ ligands in a small proportion of native human MAO $B$ heterologously expressed in yeast (Tesson et al., 1995), and further explored in detailed kinetic and binding experiments (McDonald et al., 2010). The kinetic studies demonstrated that binding in the entrance cavity $I_{2}$ site could take place either to free enzyme or when substrate or product was bound, giving mixed inhibition patterns. However, the measured $\mathrm{K}_{\mathrm{i}}$ for 2-BFI inhibition of MAO B activity is in the $\mu \mathrm{M}$ range $(49 \mu \mathrm{M})$ (Jones et al., 2007)) presumably because only a small proportion of MAO B molecules have the correct conformation for the high affinity binding. Molecular dynamics looking at mobility of residues 109-112 in the adjacent "substrate cavity loop" (residues 99-112 (Binda et al., 2003)) showed that inactivation of MAO B with TCP resulted in a stabilization of the loop that was not observed in the free enzyme, so the loop may also play a part in the high affinity binding of $\mathrm{I}_{2}$ ligands (Basile et al., 2014).

Despite the molecular studies over almost 20 years, interest in drug development for $\mathrm{I}_{2}$ sites has only recently accelerated with a compound for pain relief entering clinical trials (Lanza et al., 2014), although the analgesic effect is unlikely to be due to binding to MAO $B$ since $I_{2}$ ligands bind to multiple sites and the target for this compound is not known. New ligands enable detection and imaging studies for distribution and occupancy of $\mathrm{I}_{2}$ sites (Tyacke et al., 2012, Kealey et al., 2013, Keller and Garcia-Sevilla, 2015). Further 
development will be aided by computational methods, both for structure-function relationships and for drug-like properties to ensure brain permeation (Moraes and de Azevedo, 2012, Nikolic and Agbaba, 2012, Vucicevic et al., 2015). With better understanding of the pharmacology of $\mathrm{I}_{2}$ sites, behavioral studies are also now appearing (Qiu et al., 2014, Qiu et al., 2015).

\subsection{MAO B activity: catalysis and mechanism}

4.2.1 The MAO B catalytic cycle. The data presented in this section has accumulated over two decades, but is reiterated as important background for cellular studies and drug design. The key parameters that define enzyme activity are the steadystate rate constant $\mathrm{k}_{\mathrm{cat}}$ and the $\mathrm{K}_{\mathrm{M}}$ values for the substrates. Knowing the mechanism followed in the catalytic process is also useful in designing inhibitors. Amine is oxidized to the imine with concomitant reduction of the flavin cofactor. The reduced flavin is reoxidized by oxygen, producing $\mathrm{H}_{2} \mathrm{O}_{2}$. The imine is non-enzymically hydrolyzed to give a stable aldehyde product. Although this may seem like a simple ping-pong mechanism, the oxidative half-reaction is slow, unless a new substrate molecule is bound to the reduced MAO, as shown in Fig. 3. The rate constants for the different steps in the reaction are such that MAO in either oxidized or reduced form can bind substrate or inhibitor with different proportions in each form depending on the substrate.

Different substrates are oxidized at very different rates. Based on the kinetic parameters reviewed in (Youdim et al., 2006, Edmondson et al., 2009, Ramsay et al., 2011), MAO A and $\mathrm{MAO} B$ are equally efficient at metabolizing dopamine with $\mathrm{k}_{\mathrm{cat}} / \mathrm{K}_{\mathrm{M}}$ values greater than for other physiological substrates. With serotonin, MAO A is about 40 times better than MAO B, whereas with phenylethylamine MAO B is about 35 times better than MAO A, with both $\mathrm{k}_{\mathrm{cat}}$ and $\mathrm{K}_{\mathrm{M}}$ differences. From these kinetic measurements, it is clear that dopamine and noradrenaline are metabolized by both MAO A and MAO B, but serotonin is metabolized mainly by MAO A. Since serotonergic neurons contain mainly MAO $B$, this is consistent with a role for the MAO B in serotonergic neurons to protect mitochondria and the nerve terminals from other neurotransmitters. 


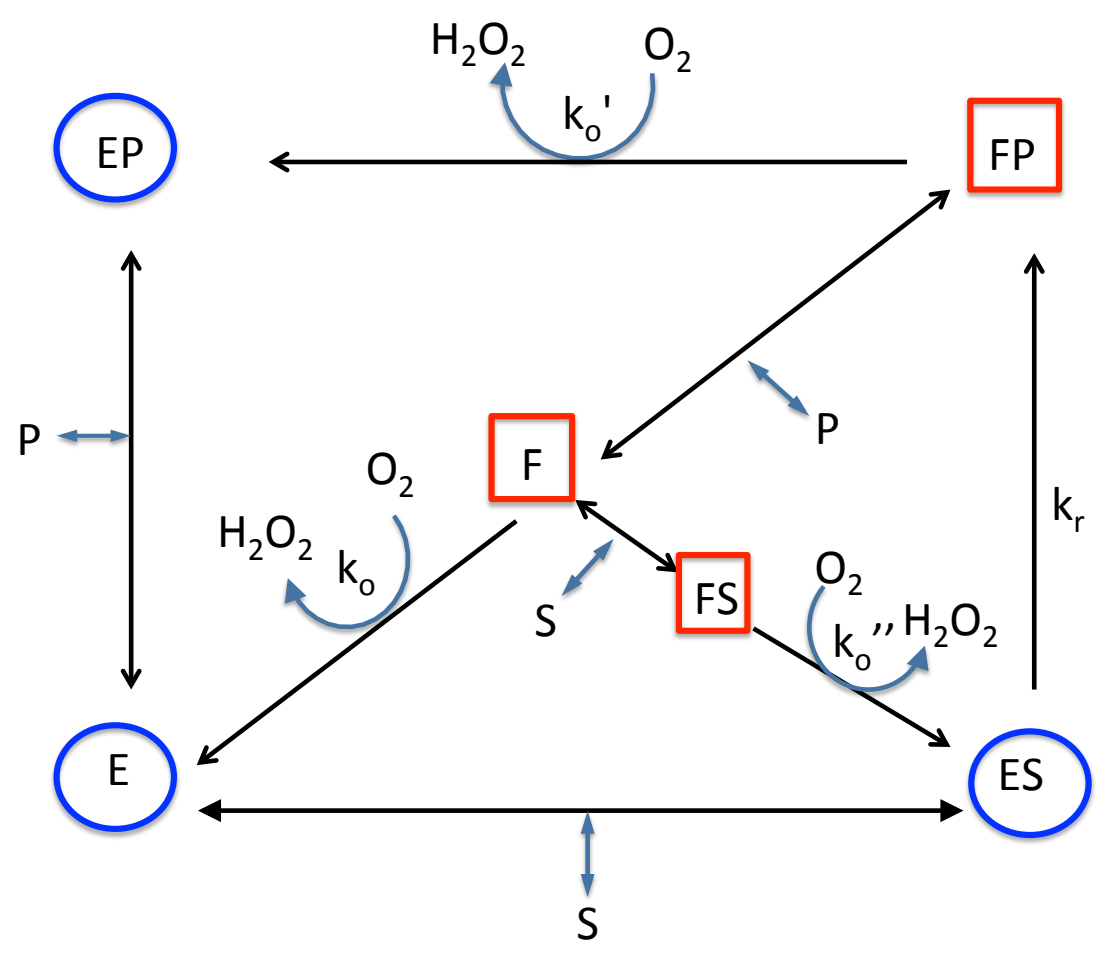

Fig. 3. Kinetic cycle of MAO B. The scheme shows two forms of MAO B (E, oxidized and F, reduced) both of which can bind substrate $(S)$ or product $(P)$ reversibly. The reduction step $\left(k_{r}\right)$ is the slowest step. There are three possible forms of the reduced enzyme (FP, F, and FS in red square boxes) each of which reacts with oxygen at a different rate $\left(\mathrm{k}_{0}, \mathrm{k}_{0}{ }^{\prime}, \mathrm{k}_{0}{ }^{\prime \prime}\right)$ to return to the equivalent oxidized form of the enzyme (in blue circles)

4.2.2 Kinetics: $\mathbf{k}_{\text {cat }}, \mathrm{K}_{\mathrm{M}}$ amines, $\mathrm{K}_{\mathrm{M}}$ oxygen. Most of the early kinetic studies, in common with many pharmacological studies, were performed in rats, where it was noted that the $K_{M}$ values for the amine substrates varied with the oxygen concentration (Fowler and Oreland, 1980). Successful cloning into Pichia pastoris (Newton-Vinson et al., 2000) enabled work on human MAO B. It is important to note that the $K_{M}$ value for oxygen is 0.33 $\mathrm{mM}$ for human MAO B (Newton-Vinson et al., 2000), higher than the concentration of oxygen in water $\left(0.215 \mathrm{mM}\right.$ at $\left.37^{\circ} \mathrm{C}\right)$. Thus, reoxidation will contribute to the steady-state reaction rate for MAO B in air-saturated buffer (McDonald et al., 2010). Any decrease in oxygen concentration in the cell will slow amine catabolism by MAO B.

In the steady state, MAO B molecules can be in either oxidized or reduced form (Fig. 3). The two forms have different affinities for the substrates (and inhibitors) (Tan and Ramsay, 1993, McDonald et al., 2010). The complex kinetics mean that the normal medicinal chemistry measure for new inhibitors, namely the $\mathrm{IC}_{50}$ value which depends on the conditions of the assay used, may not be readily comparable to in vivo conditions. Binding 
of inhibitor to both oxidized and reduced enzyme ( $E$ and $F$ in Fig. 3) was first demonstrated for amphetamine (Pearce and Roth, 1985). Using the same principles, high throughput assays now can provide sufficient information to determine routinely the $\mathrm{K}_{i}$ values for binding of inhibitors to each form (McDonald et al., 2010, Ramsay et al., 2011) (see below). The different values obtained for binding to oxidized and reduced MAO will influence the observed $\mathrm{K}_{i}$ in assessments where fewer points are used (see (Ramsay et al., 2011). The observed $K_{i}$ will vary with the substrate used because the differing rate constants for each substrate means that the steady-state population of free reduced enzyme versus free oxidized enzyme is different for each substrate. The differences in steady-state redox balance are apparent in stopped-flow monitored turnover spectrophotometry (Tan and Ramsay, 1993). This means that the in vivo effectiveness of a reversible inhibitor is not simple to predict and it will vary by cell type and brain region, depending on the most plentiful catecholamine and its concentration. Where serotonin is the main substrate as in serotonergic neurons, $M A O B$ will be mostly oxidized $\left(K_{M}\right.$ high, reduction 17 times slower then oxidation). When phenylethylamine is the main amine present, MAO B will be mostly reduced ( $\mathrm{K}_{\mathrm{M}}$ low, reduction 300 times faster than oxidation).

4.2.3 Chemical mechanism. From the deuterium isotope effects in steady state and stopped-flow monitored pre-steady state kinetic experiments, it is clear that the slowest step in the MAO A reaction is the breaking of the bond between hydrogen and the $\alpha$ carbon in the amine substrate. In MAO B, the re-oxidation of the reduced MAO B may be slower than the bond-breaking step. This is clearly seen in the rate constant for reduction of MAO B by phenylethylamine at $543 \mathrm{~s}^{-1}, 500$ times faster than the re-oxidation of reduced MAO B $\left(1 \mathrm{~s}^{-1}\right)$ (Ramsay et al., 1987). Nonetheless, a deuterium isotope effect of 8.2 on turnover (5.3 on $\mathrm{k}_{\mathrm{cat}} / \mathrm{K}_{\mathrm{M}}$ ) of benzylamine (Walker and Edmondson, 1994) indicates that the hydrogen extraction is energetically the most difficult step of the reaction. Theoretical calculations for the oxidation of dopamine give an activation free energy $\left(\Delta G^{\ddagger}\right)$ for formation of the transition state of $16.1 \mathrm{kcal} \mathrm{mol}^{-1}$ (Repic et al., 2014) in excellent agreement with the experimental value of $16.5 \mathrm{kcal} \mathrm{mol}^{-1}$ (Edmondson et al., 2009).

The controversial question is how two hydrogens are transferred from the amine to the flavin. There being no base in the active site protein sequence to accept a proton, there are three possible mechanisms for the chemical mechanism of MAO. The polar nucleophilic mechanism postulates a transient adduct to the C4a atom of the FAD 
cofactor, with the N5 then acting as a base to remove the proton. This mechanism is supported by quantitative structure-activity relationships for a series of substituted benzylamine substrates with MAO B (Walker and Edmondson, 1994). Single electron transfer followed by proton transfer is the mechanism well supported by studies on the inactivation of MAO by cyclopropylamines (Silverman, 1995) but no radical intermediate has been detected during turnover, even with slow substrates. The third mechanism, a simple hydride transfer, cannot be ruled out (Kay et al., 2007) but there is no positive evidence to support it. Indeed, the temporal separation of the carbon-hydrogen bond cleavage from the change in the nitrogen atom required as a consequence of hydride transfer (rehybridisation (MacMillar et al., 2011)) does not support a hydride transfer mechanism. In a novel approach, a synthetic chemical model successfully reproduced the catalytic properties of MAO B and provided evidence for proton abstraction after an initial charge transfer facilitated by a tyrosyl radical cation (Murray et al., 2015), but the system is an artificial one that would not necessarily follow the mechanism optimized in the protein.

Independently of the experimental approaches, theoretical chemistry can now address the question of catalytic mechanism using novel computational methods that allow consideration of the atoms involved in the chemistry at the most precise level and the surrounding protein at a lower level of detail. Using different methods, two computational approaches support either the polar nucleophilic (Abad et al., 2013) or the hydride ion transfer (Vianello et al., 2012, Repic et al., 2014). The hydride ion transfer mechanism gives the lowest activation energy making it the most likely pathway, but better experimental evidence for the transition states for each calculated mechanism would be useful.

\section{Inhibition of MAO B.}

\subsection{Irreversible and reversible inhibition of MAO B.}

The most successful inhibition of MAO B in vivo comes from drugs that inactivate the enzyme by covalent attachment. The examples shown in Table 1 illustrate the main classes: the hydrazine, acetylenic (propargyl), and cyclopropyl compounds are activated by the enzyme itself. The reactive product forms a covalent bond with the enzyme, usually to the flavin cofactor (Mitchell et al., 2001, Edmondson et al., 2009, Bonivento et al., 2010, Esteban et al., 2014). Activity in the cell is restored only by synthesis of new MAO B, a slow process with a half-life of 9 days in rat brain (Youdim and Tipton, 2002). For the best 
pharmacological effect, MAO B must be more than $90 \%$ inhibited (Fowler et al., 2005). The recovery of $\mathrm{MAO} B$ in human brain was followed using $\mathrm{PET}$, revealing a recovery period of about 40 days (Fowler et al., 2005, Fowler et al., 2015).

Table 1. Drugs that inhibit MAO B.

\begin{tabular}{|c|c|c|c|c|}
\hline Chemical type & Example & Structure & Drug name & Selectivity \\
\hline Hydrazine & $\begin{array}{l}\text { Phenelzine } \\
\text { 2-phenylethylhydrazine }\end{array}$ & & Nardil & both \\
\hline Acetylenic & $\begin{array}{l}\text { Deprenyl } \\
\text { (R)-N-methyl-N-(1-phenyl } \\
\text { propan-2-yl)prop-2-yn-1-amine }\end{array}$ & & Selegiline & $B$ \\
\hline $\begin{array}{l}\text { Cyclo- } \\
\text { propylamine }\end{array}$ & $\begin{array}{l}\text { Tranylcypromine } \\
(1 \mathrm{R}, 2 \mathrm{~S})-2- \\
\text { phenylcyclopropanamine }\end{array}$ & & Parnate & $B>A$ \\
\hline Reversible & Lazabemide & & Ro 19-6327 & B \\
\hline
\end{tabular}

Irreversible inhibition is characterized in vitro by kinetic analysis, or by determining the spectrum, mass, and crystal structure of the adduct. Irreversible inhibition is revealed in high-throughput kinetic screening of new compounds by a very much lower $I C_{50}$ after 30 minutes pre-incubation of the inhibitor with the enzyme compared to the $\mathrm{IC}_{50}$ when enzyme is added to the substrate and inhibitor at the same time. Deeper investigation will determine the time course of the inactivation (to measure $k_{\text {inact }}$ for chemical reactions or the kinetic parameters $\mathrm{K}_{\mathrm{l}}$ and $\mathrm{k}_{\text {inact }}$ for mechanism-based inhibitors) and the stability of the adduct to dilution or washing the membranes (for example, (Esteban et al., 2014)). The mass and structures of the adducts formed have been reported for some cyclopropylamines including TCP (Mitchell et al., 2001, Bonivento et al., 2010) and for several propargyl compounds (Hubalek et al., 2004, Esteban et al., 2014). The crystal structure for rasagiline, a MAO B inhibitor designed for PD, clearly shows the adduct attached to N5 of the flavin (Binda et al., 2005b).

Reversible inhibition is apparently simpler. High affinity for the MAO B active site is 
expressed as a nanomolar $\mathrm{K}_{\mathrm{i}}$ in steady-state kinetics. However, the doses required to maintain $90 \%$ inhibition in competition with the endogenous substrates may make these reversible inhibitors less useful for drug administration. Only labazemide, with a nanomolar $\mathrm{K}_{i}$ as a result of the slow dissociation of its complex with MAO $B$, along with moclobemide for MAO A have been used in the clinic. Many medicinal chemistry groups are nonetheless pursuing the search for a high affinity reversible inhibitor for MAO B. The chemical families and lead structures had been reviewed recently (Carradori and Silvestri, 2015).

\subsection{Multi-target drugs}

Methodical structure-based drug design with experimental screening against several targets is being used to generate promising MTDL candidates for the treatment of complex neurological diseases such as PD and AD. MAO B inhibition is a key part of molecules such as rasagiline used for PD (McCormack, 2014) and in trials for AD. For example, ladostigil combines part of rivastigmine to inhibit acetylcholinesterase with rasagiline to inhibit MAO (Geldenhuys and Van der Schyf, 2013). An added benefit is the neuroprotective effect seen with most propargyl compounds, although it is thought to be a non-MAO related effect of the propargyl moiety (Naoi and Maruyama, 2010). The question of how neuroprotection is achieved is currently being investigated, with new possible influences such as interaction with pro- and anti-apoptotic pathways (Zheng et al., 2005, Hara et al., 2006, Naoi et al., 2013, Wu et al., 2015).

One source of oxidative stress is the increased iron present in AD brains (Zecca et al., 2004). The brain-permeable $M 30$, combines multiple features including an iron chelator and a MAO inhibitor (Youdim, 2006, Kupershmidt et al., 2012, Youdim, 2013). M30 irreversibly inhibits both $\mathrm{MAO} A$ and $B$ with $\mathrm{IC}_{50}$ values of $0.037 \mu \mathrm{M}$ and $0.57 \mu \mathrm{M}$ respectively (Zheng et al., 2005). Taking the M30 molecule further, an acetylcholinesterase inhibitor was added, giving M30D, now being characterized for AD treatment. M30D is metabolized to M30 by acetylcholinesterase ensuring that the chelating activity is released only in the nervous tissue and thus decreasing toxicity in the periphery (Zheng et al., 2010). Similar aims to design inhibition of both cholinesterases and monoamine oxidases into one compound resulted in PF1901N (Bolea et al., 2014) or in aminocoumarins (Farina et al., 2015) both of which also show neuroprotective effects. Other newer MTDL with MAO B inhibition profiles include tacrine-coumarin hybrids (Xie et al., 2015) and hydroxyl-quinoline hybrids (Wang et al., 2014). Combinations that target 
MAO in combination with receptors have also begun to appear (Stoessel et al., 2013, Nikolic et al., 2015).

\section{Concluding remarks}

MAO $B$ inhibition has proven in vivo influence over amine metabolism and behavior. MAO $B$ inhibition has anti-depressant activity and spares dopamine in PD. While the gold standard for measuring inhibition of MAO B in the brain is PET scanning, platelet activity remains a useful, cheaper alternative for investigation of variations in MAO B activity that arise not from neurodegeneration but from genetic causes. The association of low MAO B activity with predisposition to addiction is supported by some studies, but only the MAO A epigenetic pattern has been identified as associated with addiction (Philibert et al., 2010). The increase of MAO B activity in ageing brain resulting in increased oxidative stress suggests that the hunt for new effective brain-targeted MAO B inhibitors will continue. Although new reversible inhibitors have been designed, there is no indication that they will be successful in vivo. In the meantime, the traditional irreversible inhibitors are effective and well understood drugs.

\section{Acknowledgements}

This work was supported by collaborations enabled by COST Action CM1103, "Structure-based drug design for diagnosis and treatment of neurological diseases: dissecting and modulating complex function in the monoaminergic systems of the brain". I thank the Royal Society of Edinburgh and the National Academy of Slovenia for an International Exchange award (July 2015) to facilitate integration of computational and experimental work on monoamine oxidases. 


\section{REFERENCES}

Abad E, Zenn RK, Kaestner J. Reaction mechanism of monoamine oxidase from QM/MM calculations. Journal of Physical Chemistry B 2013;117:14238-46.

Adolfsson R, Gottfries CG, Oreland L, Wiberg A, Winblad B. Increased activity of brain and platelet monoamine-oxidase in dementia of Alzheimer type. Life Sci 1980;27:1029-34.

Aklillu E, Karlsson S, Zachrisson OO, Ozdemir V, Agren H. Association of MAOA gene functional promoter polymorphism with CSF dopamine turnover and atypical depression.

Pharmacogenetics and Genomics 2009;19:267-75.

Aluf Y, Vaya J, Khatib S, Loboda Y, Finberg JPM. Selective inhibition of monoamine oxidase A or $B$ reduces striatal oxidative stress in rats with partial depletion of the nigro-striatal dopaminergic pathway. Neuropharmacology 2013;65:48-57.

Andreou D, Soderman E, Axelsson T, Sedvall GC, Terenius L, Agartz I, et al. Polymorphisms in genes implicated in dopamine, serotonin and noradrenalin metabolism suggest association with cerebrospinal fluid monoamine metabolite concentrations in psychosis. Behavioral and Brain Functions 2014;10.

Balciuniene J, Emilsson L, Oreland L, Pettersson U, Jazin EE. Investigation of the functional effect of monoamine oxidase polymorphisms in human brain. Hum Genet 2002;110:1-7.

Basile L, Pappalardo M, Guccione S, Milardi D, Ramsay RR. Computational comparison of imidazoline association with the 12 binding site in human monoamine oxidases. J Chem Inf Model 2014;54:1200-7.

Bautista-Aguilera OM, Samadi A, Chioua M, Nikolic K, Filipic S, Agbaba D, et al. N-Methyl-N-((1methyl-5-(3-(1-(2-methylbenzyl)piperidin-4yl)propoxy)-1H- indol-2-yl)methyl)prop-2-yn-1amine, a New Cholinesterase and Monoamine Oxidase Dual. J Med Chem 2014;57:10455-63.

Bazzu G, Rocchitta G, Migheli R, Alvau MD, Zinellu M, Puggioni G, et al. Effects of the neurotoxin MPTP and pargyline protection on extracellular energy metabolites and dopamine levels in the striatum of freely moving rats. Brain Res 2013;1538:159-71.

Beaulieu J-M, Espinoza S, Gainetdinov RR. Dopamine receptors - IUPHAR Review 13. Br J Pharmacol 2015;172:1-23.

Bianchi P, Kunduzova O, Masini E, Cambon C, Bani D, Raimondi L, et al. Oxidative stress by monoamine oxidase mediates receptor-independent cardiomyocyte apoptosis by serotonin and postischemic myocardial injury. Circulation 2005;112:3297-305.

Binda C, De Colibus L, Edmondson DE, Mattevi A. 2BYB: Human monoamine oxidase B in complex with deprenyl. Protein Data Bank 2005a.

Binda C, Hubalek F, Li M, Herzig Y, Sterling J, Edmondson DE, et al. Binding of rasagiline-related inhibitors to human monoamine oxidases. a kinetic and crystallographic analysis. J Med Chem 2005b;48:8148-54.

Binda C, Li M, Hubalek F, Restelli N, Edmondson DE, Mattevi A. Insights into the mode of inhibition of human mitochondrial monoamine oxidase $B$ from high-resolution crystal structures. Proc Natl Acad Sci U S A 2003;100:9750-5.

Bolea I, Colivicchi MA, Ballini C, Marco-Contelles J, Tipton KF, Unzeta M, et al. Neuroprotective Effects of the MAO B Inhibitor, PF9601N, in an In Vivo Model of Excitotoxicity. CNS Neuroscience \& Therapeutics 2014;20:641-50. 
Bonivento D, Milczek EM, McDonald GR, Binda C, Holt A, Edmondson DE, et al. Potentiation of ligand binding through cooperative effects in monoamine oxidase B. J Biol Chem 2010;285:36849-56.

Bortolato M, Godar SC, Davarian S, Chen K, Shih JC. Behavioral disinhibition and reduced anxiety-like behaviors in monoamine oxidase B-deficient mice. Neuropsychopharmacology 2009;34:2746-57.

Bortolato M, Shih JC. Behavioral outcomes of monoamine oxidase deficiency: preclinical and clinical evidence. international Review of Neurobiology 2011;100:13-42.

Brunner HG, Nelen M, Breakefield XO, Ropers HH, Vanoost BA. Abnormal behavior associated with a point mutation in the structural gene for monoamine oxidase-A. Science 1993;262:57880 .

Butcher SP, Fairbrother IS, Kelly JS, Arbuthnott GW. Effects of selective monoamine-oxidase inhibitors on the in vivo release and metabolism of dopamine in the rat striatum. $J$ Neurochem 1990;55:981-8.

Carradori S, Silvestri R. New frontiers in selective human MAO B inhibitors. J Med Chem 2015;58:6717-32.

Chen K, Holschneider DP, Wu WH, Rebrin I, Shih JC. A spontaneous point mutation produces monoamine oxidase A/B knock-out mice with greatly elevated monoamines and anxiety-like behavior. J Biol Chem 2004;279:39645-52.

Coccini T, Castoldi AF, Gandini C, Randine G, Vittadini G, Baiardi P, et al. Platelet monoamine oxidase $B$ activity as a state marker for alcoholism: Trend over time during withdrawal and influence of smoking and gender. Alcohol Alcohol 2002;37:566-72.

Dammann G, Teschler S, Haag T, Altmueller F, Tuczek F, Dammann RH. Increased DNA methylation of neuropsychiatric genes occurs in borderline personality disorder. Epigenetics 2011;6:1454-62.

De Benedetto GE, Fico D, Pennetta A, Malitesta C, Nicolardi G, Lofrumento DD, et al. A rapid and simple method for the determination of 3,4-dihydroxyphenylacetic acid, norepinephrine, dopamine, and serotonin in mouse brain homogenate by HPLC with fluorimetric detection. J Pharm Biomed Anal 2014;98:266-70.

Deftereos SN, Dodou E, Andronis C, Persidis A. From depression to neurodegeneration and heart failure: re-examining the potential of MAO inhibitors. Expert Review of Clinical Pharmacology 2012;5:413-25.

Dhondt JL, Forzy G. Usual values for 5-hydroxy-indol acetic acid and homovanillic acid in cerebrospinal fluid. Annales De Biologie Clinique 2003;61:69-75.

Dingemanse J, Kneer J, Wallnofer A, Kettler R, Zurcher G, Koulu M, et al. Pharmacokineticpharmacodynamic interactions between two selective monoamine oxidase inhibitors: Moclobemide and selegiline. Clin Neuropharmacol 1996;19:399-414.

Edmondson DE, Binda C, Mattevi A. Structural insights into the mechanism of amine oxidation by monoamine oxidases A and B. Arch Biochem Biophys 2007;464:269-76.

Edmondson DE, Binda C, Wang J, Upadhyay AK, Mattevi A. Molecular and mechanistic properties of the membrane-bound mitochondrial monoamine oxidases. Biochemistry 2009;48:4220-30.

Esteban G, Allan J, Samadi A, Mattevi A, Unzeta M, Marco-Contelles J, et al. Kinetic and structural analysis of the irreversible inhibition of human monoamine oxidases by ASS234, a multi-target 
compound designed for use in Alzheimer's disease. BBA-Proteins Proteomics 2014;1844:1104-10.

Farina R, Pisani L, Catto M, Nicolotti O, Gadaleta D, Denora N, et al. Structure-Based Design and Optimization of Multitarget-Directed 2H-Chromen-2-one Derivatives as Potent Inhibitors of Monoamine Oxidase B and Cholinesterases. J Med Chem 2015;58:5561-78.

Fisar Z, Hroudova J, Raboch J. Inhibition of monoamine oxidase activity by antidepressants and mood stabilizers. Neuroendocrinology Letters 2010;31:645-56.

Flik G, Folgering JHA, Cremers TIHF, Westerink BHC, Dremencov E. Interaction between brain histamine and serotonin, norepinephrine, and dopamine systems: In vivo microdialysis and electrophysiology study. J Mol Neurosci 2015;56:320-8.

Fowler CJ, Oreland L. The nature of the substrate-selective interaction between rat-liver mitochondrial monoamine-oxidase and oxygen. Biochem Pharmacol 1980;29:2225-33.

Fowler JS, Logan J, Shumay E, Alia-Klein N, Wang G-J, Volkow ND. Monoamine oxidase: radiotracer chemistry and human studies. J Label Compd Radiopharm 2015;58:51-64.

Fowler JS, Logan J, Volkow ND, Wang GJ. Translational neuroimaging: Positron emission tomography studies of monoamine oxidase. Molecular Imaging and Biology 2005;7:377-87.

Fowler JS, Volkow ND, Wang GJ, Pappas N, Logan J, MacGregor R, et al. Inhibition of monoamine oxidase B in the brains of smokers. Nature 1996;379:733-6.

Gal S, Zheng $\mathrm{H}$, Fridkin M, Youdim MBH. Novel multifunctional neuroprotective iron chelatormonoamine oxidase inhibitor drugs for neurodegenerative diseases. In vivo selective brain monoamine oxidase inhibition and prevention of MPTP-induced striatal dopamine depletion. J Neurochem 2005;95:79-88.

Garpenstrand H, Ekblom J, Forslund K, Rylander G, Oreland L. Platelet monoamine oxidase activity is related to MAOB intron 13 genotype. J Neural Transm 2000;107:523-30.

Geldenhuys WJ, Van der Schyf CJ. Rationally designed multi-targeted agents against neurodegenerative diseases. Curr Med Chem 2013;20:1662-72.

Gillman PK. Advances pertaining to the pharmacology and interactions of irreversible nonselective monoamine oxidase inhibitors. J Clin Psychopharmacol 2011;31:66-74.

Gu H, Varner EL, Groskreutz SR, Michael AC, Weber SG. In vivo monitoring of dopamine by microdialysis with 1 min temporal resolution using online capillary liquid chromatography with electrochemical detection. Analytical Chemistry 2015;87:6088-94.

Hara MR, Thomas B, Cascio MB, Bae BI, Hester LD, Dawson VL, et al. Neuroprotection by pharmacologic blockade of the GAPDH death cascade. Proc Natl Acad Sci U S A 2006;103:3887-9.

Hauptmann N, Grimsby J, Shih JC, Cadenas E. The metabolism of tyramine by monoamine oxidase A/B causes oxidative damage to mitochondrial DNA. Arch Biochem Biophys 1996;335:295-304.

Holschneider DP, Chen K, Seif I, Shih JC. Biochemical, behavioral, physiologic, and neurodevelopmental changes in mice deficient in monoamine oxidase A or B. Brain Res Bull 2001;56:453-62. 
Hubalek F, Binda C, Li M, Herzig Y, Sterling J, Youdim MBH, et al. Inactivation of purified human recombinant monoamine oxidases $A$ and $B$ by rasagiline and its analogues. $J$ Med Chem 2004;47:1760-6.

Hyland K. Clinical utility of monoamine neurotransmitter metabolite analysis in cerebrospinal fluid. Clinical Chemistry 2008;54:633-41.

Ihle EC, van der Hart M, Jongsma M, Tecott LH, Doupe AJ. Dopamine physiology in the basal ganglia of male zebra finches during social stimulation. Eur J Neurosci 2015;41:1506-14.

Jones TZE, Giurato L, Guccione S, Ramsay RR. Interactions of imidazoline ligands with the active site of purified monoamine oxidase A. Febs J 2007;274:1567-75.

Kaludercic N, Mialet-Perez J, Paolocci N, Parini A, Di Lisa F. Monoamine oxidases as sources of oxidants in the heart. Journal of Molecular and Cellular Cardiology 2014;73:34-42.

Kay CWM, El Mkami H, Molla G, Pollegioni L, Ramsay RR. Characterization of the covalently bound anionic flavin radical in monoamine oxidase a by electron paramagnetic resonance. $\mathrm{J}$ Am Chem Soc 2007;129:16091-7.

Kealey S, Turner EM, Husbands SM, Salinas CA, Jakobsen S, Tyacke RJ, et al. Imaging imidazoline-I-2 binding sites in porcine brain using C-11-BU99008. Journal of Nuclear Medicine 2013;54:139-44.

Keller B, Garcia-Sevilla JA. Immunodetection and subcellular distribution of imidazoline receptor proteins with three antibodies in mouse and human brains: Effects of treatments with I-1- and I-2-imidazoline drugs. J Psychopharmacol 2015;29:996-1012.

Kennedy BP, Ziegler MG, Alford M, Hansen LA, Thal LJ, Masliah E. Early and persistent alterations in prefrontal cortex MAO A and B in Alzheimer's disease. J Neural Transm 2003;110:789-801.

Kupershmidt L, Amit T, Bar-Am O, Weinreb O, Youdim MBH. Multi-target, neuroprotective and neurorestorative M30 improves cognitive impairment and reduces alzheimer's-like neuropathology and age-related alterations in mice. Molecular Neurobiology 2012;46:217-20.

Lamensdorf I, Youdim MBH, Finberg JPM. Effect of long-term treatment with selective monoamine oxidase $A$ and $B$ inhibitors on dopamine release from rat striatum in vivo. J Neurochem 1996;67:1532-9.

Lanza M, Ferrari F, Menghetti I, Tremolada D, Caselli G. Modulation of imidazoline I-2 binding sites by CR4056 relieves postoperative hyperalgesia in male and female rats. Br J Pharmacol 2014;171:3693-701.

Launay J-M, Del Pino M, Chironi G, Callebert J, Peoc'h K, Megnien J-L, et al. Smoking induces long-lasting effects through a monoamine-oxidase epigenetic regulation. PLoS ONE 2009;4:e7959. doi:10.1371/journal.pone.0007959.

Lenders JWM, Eisenhofer G, Abeling N, Berger W, Murphy DL, Konings CH, et al. Specific genetic deficiencies of the $A$ and $B$ isoenzymes of monoamine oxidase are characterized by distinct neurochemical and clinical phenotypes. Journal of Clinical Investigation 1996;97:1010-9.

Liu Y, Wang Z, Zhang B. The relationship between monoamine oxidase B (MAOB) A644G polymorphism and Parkinson disease risk: a meta-analysis. Annals of Saudi Medicine 2014;34:12-7.

Lum CT, Stahl SM. Opportunities for reversible inhibitors of monoamine oxidase-A (RIMAs) in the treatment of depression. Cns Spectrums 2012;17:107-20. 
MacMillar S, Edmondson DE, Matsson O. Nitrogen Kinetic Isotope Effects for the Monoamine Oxidase B-Catalyzed Oxidation of Benzylamine and (1,1-H-2(2))Benzylamine: Nitrogen Rehybridization and CH Bond Cleavage Are Not Concerted. J Am Chem Soc 2011;133:1231921.

Malmlof T, Feltmann K, Konradsson-Geuken A, Schneider F, Alken R-G, Svensson TH, et al. Deuterium-substituted L-DOPA displays increased behavioral potency and dopamine output in an animal model of Parkinson's disease: comparison with the effects produced by L-DOPA and an MAO B inhibitor. J Neural Transm 2015;122:259-72.

Manuck SB, Flory JD, Ferrell RE, Mann JJ, Muldoon MF. A regulatory polymorphism of the monoamine oxidase-A gene may be associated with variability in aggression, impulsivity, and central nervous system serotonergic responsivity. Psychiatry Res 2000;95:9-23.

McCormack PL. Rasagiline: A review of its use in the treatment of idiopathic Parkinson's Disease. CNS Drugs 2014;28:1083-97.

McCorvy JD, Roth BL. Structure and function of serotonin G protein-coupled receptors. Pharmacol Ther 2015;150:129-42.

McDonald GR, Olivieri A, Ramsay RR, Holt A. On the formation and nature of the imidazoline I(2) binding site on human monoamine oxidase-B. Pharmacol Res 2010;62:475-88.

Mercimek-Mahmutoglu S, Sidky S, Patel J, Kyriakopoulou L, Hyland K. Retrospective review of cerebrospinal fluid catecholamine and serotonin metabolites for indications and diagnosis of neurotransmitter disorders. Mol Genet Metab 2014;111:279-80.

Meyer JH, Ginovart N, Boovariwala A, Sagrati S, Hussey D, Garcia A, et al. Elevated monoamine oxidase A levels in the brain - An explanation for the monoamine imbalance of major depression. Arch Gen Psychiatry 2006;63:1209-16.

Mitchell DJ, Nikolic D, van Breemen RB, Silverman RB. Inactivation of monoamine oxidase B by 1phenylcyclopropylamine: Mass spectral evidence for the flavin adduct. Bioorg Med Chem Lett 2001;11:1757-60.

Moraes FP, de Azevedo WF, Jr. Targeting imidazoline site on monoamine oxidase B through molecular docking simulations. Journal of Molecular Modeling 2012;18:3877-86.

Moron JA, Perez V, Pasto M, Lizcano JM, Unzeta M. FA-70, a novel selective and irreversible monoamine oxidase-A inhibitor: Effect on monoamine metabolism in mouse cerebral cortex. $J$ Pharmacol Exp Ther 2000;292:788-94.

Murphy BP, Chung Y-C, Park T-W, McGorry PD. Pharmacological treatment of primary negative symptoms in schizophrenia: A systematic review. Schizophr Res 2006;88:5-25.

Murphy DL, Sims KB, Karoum F, Delachapelle A, Norio R, Sankila EM, et al. Marked amine and amine metabolite changes in Norrie disease patients with an X-chromosomal deletion affecting monoamine-oxidase. J Neurochem 1990;54:242-7.

Murray AT, Dowley MJH, Pradaux-Caggiano F, Baldansuren A, Fielding AJ, Tuna F, et al. Catalytic Amine Oxidation under Ambient Aerobic Conditions: Mimicry of Monoamine Oxidase B. Angewandte Chemie-International Edition 2015;54:8997-9000.

Naoi M, Maruyama W. Monoamine Oxidase inhibitors as neuroprotective agents in age-dependent neurodegenerative disorders. Curr Pharm Design 2010;16:2799-817. 
Naoi M, Maruyama W, Inaba-Hasegawa K. Revelation in the neuroprotective functions of rasagiline and selegiline: the induction of distinct genes by different mechanisms. Expert Review of Neurotherapeutics 2013;13:671-84.

Newton-Vinson $\mathrm{P}$, Hubalek F, Edmondson DE. High-level expression of human liver monoamine oxidase B in Pichia pastoris. Protein Expr Purif 2000;20:334-45.

Nicotra A, Pierucci F, Parvez H, Senatori O. Monoamine Oxidase Expression During Development and Aging. NeuroToxicology 2004;25:155-65.

Nikolic K, Agbaba D. Pharmacophore Development and SAR Studies of Imidazoline Receptor Ligands. Mini-Reviews in Medicinal Chemistry 2012;12:1542-55.

Nikolic K, Mavridis L, Bautista-Aguilera OM, Marco-Contelles J, Stark H, Carreiras MdC, et al. Predicting targets of compounds against neurological diseases using cheminformatic methodology. J Comput-Aided Mol Des 2015;29:183-98.

Ooi J, Hayden MR, Pouladi MA. Inhibition of Excessive Monoamine Oxidase A/B Activity Protects Against Stress-induced Neuronal Death in Huntington Disease. Molecular Neurobiology 2015;52:1850-61.

Oreland L. Platelet monoamine oxidase, personality and alcoholism: The rise, fall and resurrection. NeuroToxicology 2004;25:79-89.

Oreland L, Hallman J. The correlation between platelet MAO activity and personality: Short review of findings and a discussion on possible mechanisms. Progress in Brain Research 1995;106: 77-84.

Oreland L, Nilsson K, Damberg M, Hallman J. Monoamine oxidases - activities, genotypes and the shaping of behaviour. J Neural Transm 2007;114:817-22.

Pearce LB, Roth JA. Human-Brain Monoamine-Oxidase Type-B - Mechanism of Deamination as Probed by Steady-State Methods. Biochemistry 1985;24:1821-6.

Philibert RA, Beach SRH, Gunter TD, Brody GH, Madan A, Gerrard M. The effect of smoking on MAOA promoter methylation in DNA prepared from lymphoblasts and whole blood. American Journal of Medical Genetics Part B-Neuropsychiatric Genetics 2010;153B:619-28.

Qiu Y, Thorn DA, Zhang Y, He X, Li J-X. Behavioral effects of the imidazoline I-2 receptor ligand BU99006 in rats. Behav Pharmacol 2014;25:130-6.

Qiu Y, Zhang Y, Li J-X. Discriminative stimulus effects of the imidazoline I-2 receptor ligands BU224 and phenyzoline in rats. Eur J Pharmacol 2015;749:133-41.

Ramsay RR. Monoamine Oxidases: The biochemistry of the proteins as targets in medicinal chemistry and drug discovery. Curr Top Med Chem 2012;12:2189-209.

Ramsay RR, Koerber SC, Singer TP. Stopped-flow studies on the mechanism of oxidation of Nmethyl- 4-phenyltetrahydropyridine by bovine liver Monoamine Oxidase-B. Biochemistry 1987;26:3045-50.

Ramsay RR, Olivieri A, Holt A. An improved approach to steady-state analysis of monoamine oxidases. J Neural Transm 2011;118:1003-19.

Repic M, Vianello R, Purg M, Duarte F, Bauer P, Kamerlin SCL, et al. Empirical valence bond simulations of the hydride transfer step in the monoamine oxidase $B$ catalyzed metabolism of dopamine. Proteins-Structure Function and Bioinformatics 2014;82:3347-55. 
Sader-Mazbar O, Loboda Y, Rabey MJ, Finberg JPM. Increased L-DOPA-derived dopamine following selective MAO-A or -B inhibition in rat striatum depleted of dopaminergic and serotonergic innervation. Br J Pharmacol 2013;170:999-1013.

Sharman JL, Mpamhanga CP, Spedding M, Germain P, Staels B, Dacquet C, et al. IUPHAR-DB: new receptors and tools for easy searching and visualization of pharmacological data. Nucleic Acids Research 2011;39:D534-D8.

Shih JC, Chen K. Regulation of MAO-A and MAO B gene expression. Curr Med Chem 2004;11:1995-2005.

Shih JC, Chen K, Ridd MJ. Monoamine oxidase: From genes to behavior. Annu Rev Neurosci 1999;22:197-217.

Shih JC, Wu JB, Chen K. Transcriptional regulation and multiple functions of MAO genes. J Neural Transm 2011;118:979-86.

Shumay E, Logan J, Volkow ND, Fowler JS. Evidence that the methylation state of the monoamine oxidase A (MAOA) gene predicts brain activity of MAO A enzyme in healthy men. Epigenetics 2012;7:1151-60.

Silverman RB. Radical ideas about monoamine-oxidase. Accounts Chem Res 1995;28:335-42.

Song MS, Matveychuk D, MacKenzie EM, Duchcherer M, Mousseau DD, Baker GB. An update on amine oxidase inhibitors: Multifaceted drugs. Prog Neuro-Psychopharmacol Biol Psychiatry 2013;44:118-24.

Stoessel A, Schlenk M, Hinz S, Kueppers P, Heer J, Guetschow M, et al. Dual targeting of adenosine $\mathrm{A}(2 \mathrm{~A})$ receptors and monoamine oxidase $\mathrm{B}$ by $4 \mathrm{H}-3,1$-benzothiazin-4-ones. J Med Chem 2013;56:4580-96.

Sturza A, Duicu OM, Vaduva A, Danila MD, Noveanu L, Varro A, et al. Monoamine oxidases are novel sources of cardiovascular oxidative stress in experimental diabetes. Can J Physiol Pharmacol 2015;93:555-61.

Tan AK, Ramsay RR. Substrate-specific enhancement of the oxidative half-reaction of Monoamine-Oxidase. Biochemistry 1993;32:2137-43.

Tesson F, Limon-Boulez I, Urban P, Puype M, Vandekerckhove J, Coupry I, et al. Localization of I2-imidazoline binding-sites on Monoamine Oxidases. J Biol Chem 1995;270:9856-61.

Tyacke RJ, Fisher A, Robinson ESJ, Grundt P, Turner EM, Husbands SM, et al. Evaluation and initial in vitro and ex vivo characterization of the potential positron emission tomography ligand, BU99008 (2-(4,5-Dihydro-1H-imidazol-2-yl)-1-methyl-1H-indole), for the imidazoline2 binding site. Synapse 2012;66:542-51.

Upadhyay AK, Borbat PP, Wang J, Freed JH, Edmondson DE. Determination of the oligomeric states of human and rat monoamine oxidases in the outer mitochondrial membrane and octyl beta-D-glucopyranoside micelles using pulsed dipolar electron spin resonance spectroscopy. Biochemistry 2008;47:1554-66.

Veitinger M, Oehler R, Umlauf E, Baumgartner R, Schmidt G, Gerner C, et al. A platelet protein biochip rapidly detects an Alzheimer's disease-specific phenotype. Acta Neuropathologica 2014a;128:665-77.

Veitinger M, Varga B, Guterres SB, Zellner M. Platelets, a reliable source for peripheral Alzheimer's disease biomarkers? Acta Neuropathologica Communications 2014b;2:65-. 
Vianello R, Repic M, Mavri J. How are biogenic amines metabolized by monoamine oxidases? European Journal of Organic Chemistry 2012:7057-65.

Vucicevic J, Nikolic K, Dobricic V, Agbaba D. Prediction of blood-brain barrier permeation of alphaadrenergic and imidazoline receptor ligands using PAMPA technique and quantitativestructure permeability relationship analysis. European Journal of Pharmaceutical Sciences 2015;68:94-105.

Walker MC, Edmondson DE. Structure-activity-relationships in the oxidation of benzylamine analogs by bovine liver mitochondrial monoamine-oxidase-B. Biochemistry 1994;33:7088-98.

Wang L, Esteban G, Ojima M, Bautista-Aguilera OM, Inokuchi T, Moraleda I, et al. Donepezil plus propargylamine+8-hydroxyquinoline hybrids as new multifunctional metal-chelators, ChE and MAO inhibitors for the potential treatment of Alzheimer's disease. Eur J Med Chem 2014;80:543-61.

Weinreb O, Badinter F, Amit T, Bar-Am O, Youdim MBH. Effect of long-term treatment with rasagiline on cognitive deficits and related molecular cascades in aged mice. Neurobiology of Aging 2015;36:2628-36.

Wong WK, Chen K, Shih JC. Decreased methylation and transcription repressor Sp3 up-regulated human monoamine oxidase (MAO) B expression during Caco-2 differentiation. J Biol Chem 2003;278:36227-35.

Woodard CM, Campos BA, Kuo S-H, Nirenberg MJ, Nestor MW, Zimmer M, et al. iPSC-derived dopamine neurons reveal differences between monozygotic twins discordant for Parkinson's Disease. Cell Reports 2014;9:1173-82.

Wu Y, Kazumura K, Maruyama W, Osawa T, Naoi M. Rasagiline and selegiline suppress calcium efflux from mitochondria by PK11195-induced opening of mitochondrial permeability transition pore: a novel anti-apoptotic function for neuroprotection. J Neural Transm 2015;122:1399-407.

Xie S-S, Wang X, Jiang N, Yu W, Wang KDG, Lan J-S, et al. Multi-target tacrine-coumarin hybrids: Cholinesterase and monoamine oxidase $B$ inhibition properties against Alzheimer's disease. Eur J Med Chem 2015;95:153-65.

Youdim $\mathrm{MBH}$. The path from anti Parkinson drug selegiline and rasagiline to multi-functional neuroprotective anti Alzheimer drugs ladostigil and M30. Current Alzheimer Research 2006;3:541-50.

Youdim MBH. Multi target neuroprotective and neurorestorative anti-Parkinson and anti-Alzheimer drugs ladostigil and m30 derived from rasagiline. Experimental Neurobiology 2013;22:1-10.

Youdim MBH, Edmondson D, Tipton KF. The therapeutic potential of monoamine oxidase inhibitors. Nat Rev Neurosci 2006;7:295-309.

Youdim MBH, Finberg JP. Implications of MAO-A and MAO-B inhibition for antidepressant therapy. Modern problems of pharmacopsychiatry 1983;19:63-74.

Youdim MBH, Reiderer P. Monoamine Oxidases and Their Inhibitors: Academic Press; 2011.

Youdim MBH, Tipton KF. Rat striatal monoamine oxidase-B inhibition by I-deprenyl and rasagiline: its relationship to 2-phenylethylamine-induced stereotypy and Parkinson's disease.

Parkinsonism \& Related Disorders 2002;8:247-53.

Zajecka JM, Zajecka AM. A clinical overview of monoamine oxidase inhibitors: Pharmacological profile, efficacy, safety/tolerability, and strategies for successful outcomes in the management of major depressive disorders. Psychiatric Annals 2014;44:513-23. 
Zecca L, Youdim MBH, Riederer P, Connor JR, Crichton RR. Iron, brain ageing and neurodegenerative disorders. Nat Rev Neurosci 2004;5:863-73.

Zellner M, Baureder M, Rappold E, Bugert P, Kotzailias N, Babeluk R, et al. Comparative platelet proteome analysis reveals an increase of monoamine oxidase-B protein expression in Alzheimer's disease but not in non-demented Parkinson's disease patients. Journal of Proteomics 2012;75:2080-92.

Zheng $\mathrm{H}$, Amit T, Bar-Am O, Fridkin M, Youdim MBH, Mandel SA. From anti-parkinson's drug rasagiline to novel multitarget iron chelators with acetylcholinesterase and monoamine oxidase inhibitory and neuroprotective properties for Alzheimer's Disease. Journal of Alzheimers Disease 2012;30:1-16.

Zheng H, Gal S, Weiner LM, Bar-Am O, Warshawsky A, Fridkin M, et al. Novel multifunctional neuroprotective iron chelator-monoamine oxidase inhibitor drugs for neurodegenerative diseases: in vitro studies on antioxidant activity, prevention of lipid peroxide formation and monoamine oxidase inhibition. J Neurochem 2005;95:68-78.

Zheng $\mathrm{H}$, Youdim MBH, Fridkin M. Site-Activated Chelators Targeting Acetylcholinesterase and Monoamine Oxidase for Alzheimer's Therapy. ACS Chemical Biology 2010;5:603-10. 